\title{
Clinical Evaluation of 3D High Resolution Late Enhancement using Image-Based Navigation
}

Konstantinos Bratis ${ }^{1 *}$, Chrysanthos Grigoratos ${ }^{1}$, Marcus Henningsson ${ }^{1}$, Matteo Dell'Omodarme ${ }^{2}$, Rene M Botnar ${ }^{1}$, Eike Nagel ${ }^{1}$

From 19th Annual SCMR Scientific Sessions

Los Angeles, CA, USA. 27-30 January 2016

\section{Objective}

To prospectively assess the diagnostic performance of high resolution image-navigated 3-dimensional late gadolinium enhancement (iNAV-3D LGE) magnetic resonance imaging (CMR) for the detection of myocardial necrosis in a routine clinical setting.

\section{Background}

iNAV-3D LGE is a novel CMR technique which allows for direct respiratory motion correction of the heart.
However, its performance in real-life clinical scenarios has not yet been established.

\section{Methods}

23 consecutive patients referred for CMR examination including scar imaging were prospectively enrolled. Gadolinium enhanced $(0.20 \mathrm{mmol} / \mathrm{kg}$ Gd-DTPA) navigated high resolution ( $2 \mathrm{~mm} 3$ isotropic) 3D T1-weighted gradient-echo inversion recovery sequence using imagebased navigation in comparison with a conventional

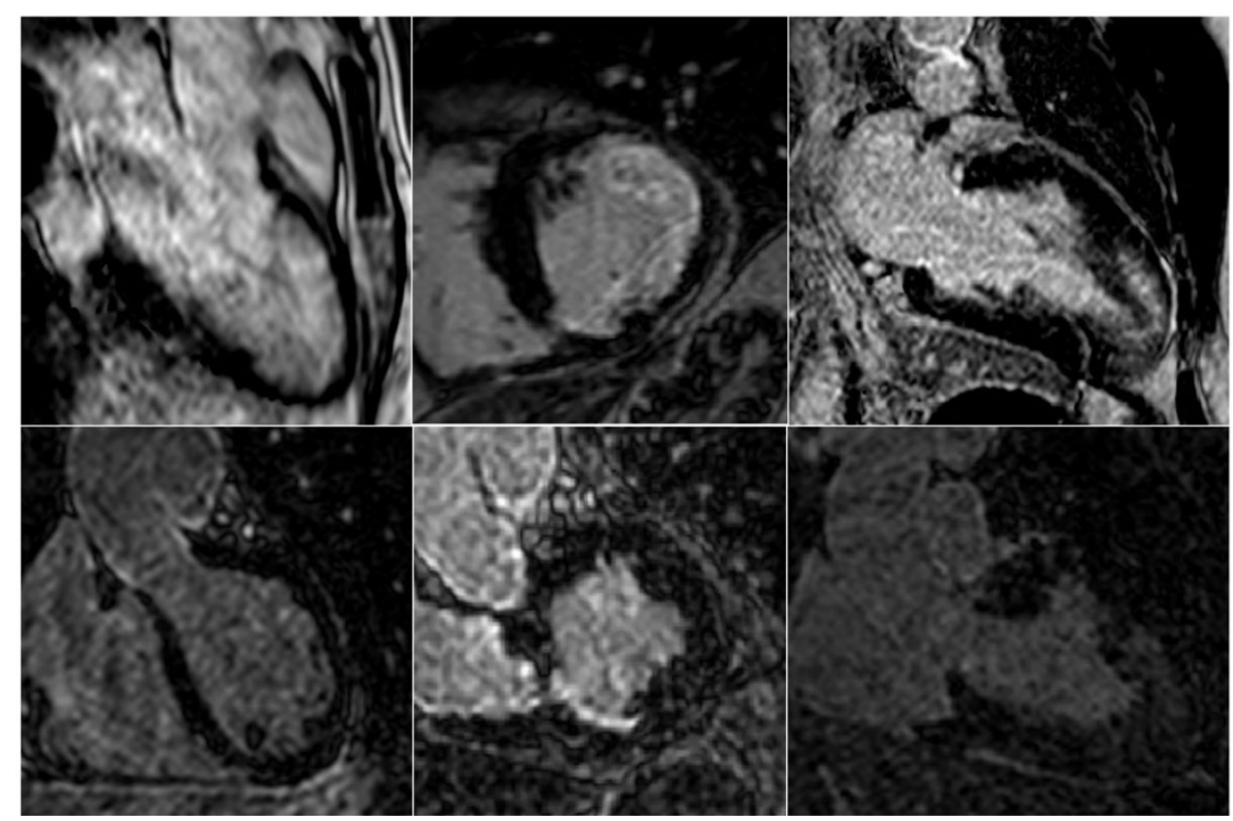

Figure 1 Selected matched images of 2D (upper row) and iNav-3D (lower row) LGE in a patient with dilated cardiomyopathy (left), ischaemic heart disease (mid) and hypertrophic cardiomyopathy (right). LGE: Late Gadolinium Enhancement

'King's College London, London, United Kingdom

Full list of author information is available at the end of the article 
Table 1 Comparison of the main diagnostic and quality assessment parameters for 2D and iNav3D LGE.

\begin{tabular}{|c|c|c|c|c|c|c|}
\hline \multicolumn{7}{|c|}{ DIAGNOSTIC PERFORMANCE } \\
\hline \multicolumn{7}{|c|}{ Global LGE detection $(p, 0.13)$} \\
\hline $2 D(n=22)$ & \multicolumn{6}{|c|}{$77 \%(17)$} \\
\hline iNav3D ( $n=22)$ & \multicolumn{6}{|c|}{$59 \%(13)$} \\
\hline \multicolumn{7}{|c|}{ Segmental LGE detection $(p, 0.28)$} \\
\hline \multicolumn{7}{|c|}{ Number of segments 012345} \\
\hline $2 D(n=352)$ & $75.9 \%(267)$ & $10.2 \%(36)$ & $3.7 \%(13)$ & $7.7 \%(27)$ & $2 \%(7)$ & $0.6 \%(2)$ \\
\hline iNav 3D ( $n=352)$ & $78.1 \%(275)$ & $8.5 \%(30)$ & $2 \%(7)$ & $7.4 \%(26)$ & $3.4 \%(12)$ & $0.6 \%(2)$ \\
\hline \multicolumn{7}{|c|}{ IMAGE QUALITY } \\
\hline Mean (SD) & \multicolumn{2}{|c|}{ 2D LGE } & \multicolumn{2}{|c|}{ iNav 3D LGE } & \multicolumn{2}{|c|}{$p$ value } \\
\hline Quality $(n=22)$ & \multicolumn{2}{|c|}{$3(0.9)$} & \multicolumn{2}{|c|}{$3.4(0.8)$} & \multicolumn{2}{|c|}{0.34} \\
\hline LGE- blood pool sharpness $(n=13)$ & \multicolumn{2}{|c|}{$2.8(0.8)$} & \multicolumn{2}{|c|}{$2.8(0.8)$} & \multicolumn{2}{|c|}{0.48} \\
\hline Myocardium- LGE sharpness $(n=13)$ & \multicolumn{2}{|c|}{$3(0.8)$} & \multicolumn{2}{|c|}{$3(0.8)$} & \multicolumn{2}{|c|}{0.48} \\
\hline
\end{tabular}

LGE: Late Gadolinium enhancement, n: number, segmental LGE detection: $0=$ no LGE, $1=$ ischaemic, $2=$ patchy, $3=$ subepicardial, $4=$ mid wall, $5=$ RV insertion points.

two-dimensional (2D LGE) sequence were performed in random order by using a 1.5-T clinical MR imaging system. Images were assessed qualitatively with regard to the detection of global and segmental LGE and transmurality. Additional subjective image quality assessement including image quality, mean LGE signal intensity and LGE-myocardial/ blood pool sharpness on a 4-point scale was performed.

\section{Results}

Interpretable images were obtained in all 2D-LGE and in 22/ 23 iNAV-3D LGE exams, resulting in a total of 22 complete sequence datasets and 352 segments. LGE was detected in 5 patients with ischemic pattern, in 8 with non-ischaemic pattern, while it was absent in 9 cases. (Figure 1) There were no significant differences between $2 \mathrm{D}$ and $3 \mathrm{D}$ data sets with regard to global and segmental LGE detection ( $p, 0.13$ and p, 0.28, respectively) and transmural extension (p, 0.84). Agreement regarding image quality was good, but $2 \mathrm{D}$ LGE presented higher LGE mean signal intensity. (Table 1) The average acquisition time for iNav-3D was from 4-6 minutes. Results were similar indepentently of the order in which the sequences were performed.

\section{Conclusions}

In this study, imaging performance and quality scores of iNAV-3D LGE images were comparable to those of 2D LGE in a prospective clinical setting. iNAV-3D LGE may potentially offer a reliable alternative for high quality scar imaging.

\section{Authors' details} 'King's College London, London, United Kingdom. ${ }^{2}$ Physics, University of
Pisa, Pisa, Italy.

Published: 27 January 2016
doi:10.1186/1532-429X-18-S1-P310

Cite this article as: Bratis et al:: Clinical Evaluation of 3D High Resolution Late Enhancement using Image-Based Navigation. Journal of Cardiovascular Magnetic Resonance 2016 18(Suppl 1):P310.
Submit your next manuscript to BioMed Central and take full advantage of:

- Convenient online submission

- Thorough peer review

- No space constraints or color figure charges

- Immediate publication on acceptance

- Inclusion in PubMed, CAS, Scopus and Google Scholar

- Research which is freely available for redistribution

Submit your manuscript at www.biomedcentral.com/submit 